\title{
Racionalidad y relativismo conceptual
}

\author{
Ambrosio Velasco
}

León Olivé, Razón y sociedad. México, Fontamara-ITAM, 1996.

E

n su libro Razón y sociedad, León Olivé desarrolla una estrategia que podríamos denominar cíclica, en la que a partir de conceptos epistémicos se analizan críticamente algunos problemas sociales fundamentales (lo cual advierte explícitamente el autor en la Introducción, p. 19), pero también, en el sentido inverso, se retoman las discusiones sobre problemas sociales, políticos, morales y tecnológicos para una mejor fundamentación de sus tesis epistemológicas. Se trata a mi manera de ver de un círculo filosófico virtuoso, en el que las conclusiones de cada ciclo permite un mejor planteamiento y desarrollo tanto de problemas epistémicos como de problemas sociales, políticos, éticos y tecnológicos.

La primera parte del ciclo inicia con la exposición de conceptos y posiciones epistemológicas fundamentales a lo largo de los tres primeros capítulos ("Razón y homogeneización social", "Los marcos conceptuales y la racionalidad" y "Objetividad y verdad"). Una vez que León Olivé ha formulado críticamente conceptos como razón, racionalidad, marco conceptual, objetividad, verdad, entre otros, a partir del capítulo cuatro y hasta el capítulo nueve, utiliza estos conceptos para analizar y discutir nociones y problemas fundamentales de diversas disciplinas sociales. En el capítulo cuatro reconstruye el concepto sociológico de jerarquía; en el quinto elabora de manera muy clara y sugerente dos conceptos claves de la teoría política: legitimidad y legitimación; en el siguiente capítulo revisa críticamente diferentes versiones de la sociobiología y reconstruye a partir de conceptos epistémicos la noción de persona como fundamento de toda teoría social. Con base en este concepto, en el capítulo siete formula y defiende sustantivamente la constitución de identidades colectivas. Retomando las categorías de persona, identidad colectiva y marco conceptual, Olivé nos ofrece en el capítulo ocho una interesante perspectiva para analizar y evaluar el cambio social; para terminar el ciclo de la epistemología a las ciencias sociales, el capítulo nueve analiza la relevancia de la tecnología en el 
cambio social. En el capítulo diez, titulado "El problema del relativismo y la verdad" el doctor Olivé regresa de nuevo al campo de los problemas epistemológicos y ontológicos, no con los mismos términos y significados de los que partió en los capítulos iniciales, sino con el andamiaje conceptual enriquecido en las discusiones sobre temas y problemas sociales. Para terminar, el capítulo once inicia de nuevo otro ciclo en el que se contextualizan las discusiones sobre relativismo y realismo en la cultura filosófica del continente americano.

En lo que sigue me centraré en el concepto de marco conceptual que propone León Olivé como una noción epistémica fundamental, así como en la aplicación de este concepto en el contexto de problemas políticos y sociales.

La formulación más completa de "marco conceptual" la podemos encontrar en el capítulo siete, que trata sobre la identidad colectiva.

[...] la noción de marco conceptual se entiende como el conjunto de recursos teóricos y conceptuales que las personas tienen a su disposición para interpretar y comprender el mundo, y también para actuar dentro de él, incluyendo en esto último la manipulación de objetos y procesos en ese mundo. Los marcos conceptuales incluyen también las normas y los valores que se requieren para hacer evaluaciones (epistémicas, morales, estéticas, etcétera). A su vez, los marcos conceptuales son construcciones sociales: son construidos, sostenidos, y en su caso transformados, como resultado de las acciones e interpretaciones de mucha gente dentro de los grupos sociales. (pp. 127-128.)

Es importante añadir que los marcos conceptuales no son meros instrumentos para conocer, actuar y juzgar, sino que también son constituyentes de la identidad personal y colectiva y, por ende, no es posible cambiar a voluntad el marco conceptual, sin que esto tenga importantes consecuencias en la identidad individual y colectiva de las personas.

León Olivé reconoce como un hecho la pluralidad de marcos conceptuales y por ende la pluralidad cultural. Este reconocimiento implica necesariamente la aceptación de un relativismo conceptual, en los diversos ámbitos del conocimiento y la actividad humanas (epistemológico, ético, político y en general cultural). Pero del reconocimiento del pluralismo cultural y de los relativismos que se derivan, no se sigue una renuncia o abandono de la razón y la racionalidad. Por el contrario, y esto es en mi opinión uno de los principales aportes del libro, el pluralismo resulta ser una condición necesaria para el ejercicio de la razón y el desarrollo de la racionalidad humana. Es precisamente este reconocimiento lo que hace al relativismo de León Olivé, un relativismo moderado.

A partir de Nicholas Rescher y Luis Villoro, León Olivé elucida el con- 
cepto de razón como una capacidad común a todos los seres humanos para conocer el mundo y realizar acciones e interacciones. Entre éstas, las interacciones dialógicas son especialmente importantes porque permiten fundamentar o justificar las acciones y creencias. La racionalidad consiste en el ejercicio de la facultad de la razón. Olivé advierte que si bien estas nociones de razón y racionalidad pueden ser universales - en cuanto se derivan de una capacidad común a todo ser humano- los criterios y principios que regulan su correcta y aceptable aplicación, son siempre dependientes de marcos conceptuales específicos y, por ende, no pueden ser universales.

Si bien lo anterior implica aceptar "la relatividad de las razones", no significa de manera alguna que cada marco conceptual define una racionalidad acabada y única, ni que la racionalidad asociada a cada marco es inconmensurable con otros principios y criterios de racionalidad. Por el contrario, y gracias a que Olivé concibe a la racionalidad como dialógica, es posible reconocer al menos dos niveles de justificación racional de las creencias y acciones: al interior de un mismo marco conceptual y entre marcos conceptuales distintos. En el primer caso, si existen condiciones de diálogo óptimas podrá llegarse a través del diálogo a un conocimiento objetivo, entendido éste como reconocimiento y aceptación pública de ciertas creencias, de acuerdo a principios y criterios de racionalidad internos a un determinado marco conceptual. Por otra parte, cuando el diálogo, en condiciones óptimas se establece entre personas pertenecientes a diferentes marcos conceptuales, cada uno con diferentes criterios de racionalidad, es posible arribar a un conocimiento verdadero, entendiendo éste como aceptación de una creencia de acuerdo a criterios de racionalidad de diferentes marcos conceptuales:

La objetividad se refiere a la aceptabilidad racional restringida a un marco conceptual específico, y la verdad se refiere a una propiedad de las proposiciones que necesariamente se preserva inter-esquemáticamente, es decir, al pasar la proposición de un marco a otro, o al ser considerada desde la perspectiva de un marco conceptual distinto, donde sin embargo la proposición puede llegar a ser inteligible con su mismo significado. (p. 67.)

Esta sugerente distinción entre objetividad y verdad habría que tomarla, creo yo, en términos graduales y no categóricos, reconociendo la posibilidad de diferentes grados de racionalidad de las creencias entre la objetividad y la verdad. De esta manera es posible entender el desarrollo racional del conocimiento, en especial del conocimiento científico, como un acercamiento a la verdad, esto es, una objetividad reconocida en marcos conceptuales cada vez más amplios y diversos. Asimismo, desde esta interpretación de la perspectiva de León 
Olivé, el acercamiento a la verdad exige un desarrollo de criterios y principios de racionalidad, en cuanto que el diálogo inter-esquemático que se exige conduce también a una revisión crítica y eventual modificación de los criterios de racionalidad particulares de cada marco conceptual involucrado y "el resultado de dicha interacción debería ser la creación de un nuevo marco conceptual derivado de los originales ..." (p. 62.) Esta consideración me parece otro de los aportes más significativos del libro al compararse con otras propuestas alternativas en filosofía de la ciencia, que, o bien restringen la racionalidad a contextos cerrados (por ejemplo, los paradigmas de Kuhn), o bien, al tratar de ampliar los márgenes de la racionalidad del cambio científico terminan por introducir criterios universales de racionalidad de dudosa existencia histórica (la tradición crítica en Popper o los programas de investigación de Lakatos). De nuevo en este punto se puede apreciar el carácter moderado del relativismo de León Olivé entre posiciones extremas.

Antes de pasar a la aplicación de los conceptos epistémicos al ámbito político quisiera brevemente exponer una objeción. León Olivé considera que para que un enunciado sea verdadero se requiere que ese enunciado sea aceptable racionalmente en todo marco conceptual en donde su significado se preserve y sea inteligible. Pero, por otra parte, ha reconocido que la inteligibilidad del enunciado y su aceptación inter-esquemática muchas veces conduce al cambio de los marcos conceptuales originales. Si esto es el caso, es muy factible que al cambiar los marcos conceptuales, también cambie el significado del enunciado original que, sin embargo, puede ser entendido y aceptado en diversos marcos conceptuales. Por ello, no considero que preservar el significado original del enunciado sea una condición necesaria para su aceptación como verdadero. (Hasta aquí el comentario crítico).

Después de elaborar el concepto de jerarquía como un orden social diferenciado con relaciones de dominación que se justifican desde determinados marcos conceptuales (cap. 5), el autor utiliza los conceptos epistémicos de objetividad y verdad, para dar cuenta de los diferentes niveles y grados en que puede justificarse un sistema político determinado. Análogamente a la objetividad del conocimiento, León Olivé llama "legitimación al asentimiento que se logra, entre sujetos racionales, mediante un ejercicio racional de disputa, dentro de los constreñimientos de un cierto marco conceptual". (p. 94.) La legitimación no excluye mecanismos de distorsión del diálogo y la comunicación que pueden pasar desapercibidos para los miembros de la comunidad en cuestión y que limitan seriamente el carácter racional de los acuerdos. Por ello, el desarrollo de la racionalidad de un sistema político requiere del diálogo crítico y plural entre diferentes marcos conceptuales, de manera análoga a como el progreso científico requiere de la discusión inter-esquemática. En el ámbito politico, la aceptabilidad inter-esquemática constituye justamente la 
legitimidad. En este contexto, también es importante señalar el carácter gradual de la distinción entre legitimación y legitimidad, así como reconocer que los progresos respecto a la legitimidad requiere de un cambio y ampliación de los marcos conceptuales desde los cuales se justifica un determinado sistema político.

A partir de este último punto y de la tesis de que los marcos conceptuales constituyen la identidad colectiva de las comunidades, León Olivé analiza diferentes problemas del cambio social, entendido éste en función de cambio de marcos conceptuales. Resulta imposible, por limitaciones de tiempo y espacio analizar siquiera someramente los problemas éticos y políticos que el autor plantea en relación al cambio social. Lo que tan sólo quisiera señalar al respecto es que esta forma de abordar el cambio social reconoce el importante papel causal de las concepciones e interpretaciones que una comunidad hace de sí misma y de su entorno, sobre los cambios de las estructuras y forma de vida social de esa misma comunidad. Con ello, me parece, Olivé introduce acertadamente como principio de la explicación del cambio social el reconocimiento del papel que los individuos tienen como personas, es decir, como agentes "capaces de iniciar cambios con un propósito, monitorear y controlar sus ejecuciones [...] de darse cuenta que hay cosas distintas a ellos y de saber lo que son". (p. 113.) Al respecto quisiera preguntarle a León Olivé su opinión sobre si las colectividades, cuya identidad está determinada por un marco conceptual, pueden como sujetos colectivos realizar operaciones reflexivas sobre los presupuestos epistemológicos, éticos, políticos y ontológicos que determinan su propia identidad, y en consecuencia si las comunidades pueden efectivamente comportarse como personas en cuanto que puedan elegir y determinar qué aceptan y qué rechazan y modifican del marco conceptual que define su identidad. Dicho de otra manera, ¿es posible que las comunidades dirijan su propio cambio, sean agentes de su propio devenir histórico? Creo que la respuesta a esta pregunta requiere seguramente de una profundización del concepto de persona, tanto en su acepción individual, como en una posible acepción colectiva. Pero esto seguramente será materia de otro libro que esperamos con mucho interés. Por lo pronto, en Razón y sociedad, León Olivé ha articulado ya de manera clara, original y sugerente muchos más problemas epistémicos y sociales de los que en esta presentación he comentado. 